\title{
Provider and Health Facility Influences on Contraceptive Adoption in Urban Pakistan
}

CONTEXT: Although the vast majority of Pakistani women are familiar with family planning methods, use of contraceptives remains low. Identifying the characteristics of family planning providers and health facilities that are associated with women's initiation of contraception may help program administrators devise interventions to increase contraceptive use.

METHODS: Logistic regression analysis of data from a survey of urban Pakistani health facilities, their clients and their staff was used to identify individual, provider and health facility characteristics that predict women's receipt of contraceptives during visits to urban clinics.

RESULTS: Women who had a secondary or higher level of education and three or more children had elevated odds of receiving a method (odds ratios, 1.8-9.3). Women had reduced odds of receiving contraceptives when visiting facilities where providers had higher levels of family planning experience. They had higher odds of receiving services at facilities that displayed educational materials about family planning than at those that did not (1.8), and those odds increased with the proportion of contraceptive methods offered that were in stock, the number of staff doctors and the number of staff members who provided family planning (1.2-2.4).

CONCLUSION: Providers should be aware of the contraceptive needs of women with all levels of education and parity. Additionally, family planning facilities may be able to increase clients' contraceptive use by providing diversity in method choice, keeping offered methods in stock, displaying informational materials, and raising stafflevels.

International Family Planning Perspectives, 2006, 32(2):71-78
By Saima Hamid and Rob

Stephenson

Saima Hamid is instructor, Health Services Academy, Islamabad, Pakistan. Rob Stephenson is assistant professor, Hubert Department of Global Health, Rollins School of Public Health, Emory University, Atlanta, GA, USA.
Between 1951 and 2004, Pakistan's population grew from 34 million to 167 million, a 400\% increase in approximately two generations. ${ }^{1}$ Although its total fertility rate (4.8) has begun to decline, ${ }^{2}$ Pakistan still has the highest rate in South Asia and continues to experience rapid population growth. ${ }^{3}$ The country's fertility rate is estimated to exceed the wanted fertility rate by more than one child, indicating a large unmet need for family planning services. ${ }^{4}$ This unmet need is the product of both a lack of adequate services and a social milieu that is generally unfavorable to the adoption of contraception. ${ }^{5}$

Nonetheless, the rate of contraceptive use in Pakistan more than doubled between 1990-1991 and 2000-2001, from $12 \%$ to $28 \% .{ }^{6}$ Moreover, knowledge of family planning in Pakistan is high: In 2000-2001, an estimated 96\% of currently married women were aware of at least one contraceptive method. ${ }^{7}$ Knowledge of how to obtain family planning methods is also high; for example, in 2000-2001, $76 \%$ of married women reported knowing a place where women could obtain a tubal ligation. ${ }^{8}$

Given the incongruity between the Pakistani population's high level of awareness of family planning and its limited use of family planning services, it may be valuable to identify the factors that have hindered Pakistanis from translating their knowledge about pregnancy prevention into regular contraceptive use. This article focuses on provider and health facility characteristics that influenced the adoption of family planning in a sample of women of reproductive age who were seeking health services in urban Pakistan.

\section{Family Planning Services in Pakistan}

Reducing population growth has become a recurrent feature of the Pakistani government's five-year plans, which were initiated in $1955 .{ }^{9}$ All responsibilities for the provision of family planning services in rural communities now rest with the Ministry of Health; community workers provide clients with oral contraceptives and condoms, while other family planning methods are available through networks of health centers. In urban areas, all modern family planning methods are available through the public sector. However, the quality of care provided by the public sector is not yet optimal; the integration of family planning services within basic and essential health services is far from complete, ${ }^{10}$ and maintaining a consistent supply of contraceptives has been a continuing problem.

Nongovernmental organizations have helped to fill these gaps in family planning service and played a vital role in improving family planning service access among marginalized groups. ${ }^{11}$ For example, the Family Planning Association of Pakistan, which has more than 540 service outlets, delivers $10-12 \%$ of the nation's family planning services and has played a leading role in Pakistan's shift toward a 
broader, holistic vision of reproductive health. ${ }^{12}$

In addition, the Ministry of Population Welfare has attempted to address the challenge of meeting family planning needs by encouraging the private sector to deliver family planning services. The private sector provides more than $70 \%$ of all health care in Pakistan but has limited involvement in family planning, ${ }^{13}$ providing a smaller share of contraceptive coverage (20\%) than either the public sector (54\%) or nongovernmental organizations (26\%). ${ }^{14}$ The private sector has generally adopted a social marketing approach, in which commercial marketing techniques are adapted to the provision of family planning services in an attempt to make products and services available and affordable to low-income groups. ${ }^{15}$

\section{Barriers to Family Planning Service Use}

In a variety of countries and settings, many demographic, socioeconomic, cultural and health experience factors have been shown to influence the use of family planning services. Demographic factors associated with reproductive health service use include younger maternal age ${ }^{16}$ and low parity ${ }^{17}$ (in Pakistan, however, women who have had at least five births have the highest rates of use and often rely on sterilization after they have achieved their desired family size $^{18}$ ). Socioeconomic factors are generally of greater importance than demographic factors in determining health service utilization, ${ }^{19}$ as they influence the ability to pay for such services; cost is a barrier to service utilization ${ }^{20}$ and also influences the choice of service provider. The most consistently reported determinant of reproductive health service utilization is a woman's level of educational attainment. ${ }^{21}$ However, many other socioeconomic indicatorsincluding urban residence, ${ }^{22}$ household living conditions, ${ }^{23}$ household income, ${ }^{24}$ women's employment in skilled work outside the home $e^{25}$ and husbands' education and occupational status ${ }^{26}$-have also been shown to be strong predictors of a woman's likelihood of using reproductive health services.

Both demographic and socioeconomic determinants of reproductive health service utilization are mediated by cultural factors. ${ }^{27}$ In Pakistan, the most notable such factors are the behavioral norms related to living in an Islamic society. The prevailing view of family honor (izzat), which requires female purity, encourages the segregation of the sexes and the confinement of women to the home (purdah), thus reducing women's access to services, particularly those involving male practitioners and those located in areas where males may be present. Moreover, two important barriers to contraceptive use in Punjab are a woman's belief that practicing contraception would conflict with her husband's fertility desires and the perception that contraceptive use is socially or culturally inappropriate. ${ }^{28}$

The supply environment is also important. Numerous studies have demonstrated an association between better service quality (or perceived quality) and increased use of family planning services. ${ }^{29}$ In a study of family planning services in Tanzania, Speizer and colleagues found that provider bias in method promotion and age restrictions on the use of some contraceptive methods impeded women from initiating contraception. ${ }^{30}$ Furthermore, a woman's experiences with health services may influence her subsequent use. ${ }^{31}$ Contact with health professionals creates both confidence in and familiarity with using health services; as a result, women are more likely to use other reproductive health services in the future.

Quality of care lays the foundation for long-term contraceptive use and greater client satisfaction. ${ }^{32}$ In a comparison of family planning services in 15 countries, Blanc and colleagues found that within a year of adopting a contraceptive method, $7-27 \%$ of women ceased to practice contraception for reasons related to the quality of the service environment. ${ }^{33}$ In Bangladesh, clients who received what they perceived as a high standard of care from fieldworkers were significantly more likely to continue contraceptive use than were those who felt that they had received poor care, although the effects of quality of care were less pronounced for initiation of contraceptive use than for continuation. ${ }^{34}$ Overall, these studies suggest that what may be most critical is the degree of trust, rapport and confidence established between the provider and the client. The physical accessibility of the service is also important: A study in rural Pakistan found that women who lived within five kilometers of two community-based health workers were significantly more likely than other women to use a modern method of contraception. ${ }^{35}$

Given that contraceptive use in Pakistan is low despite demonstrated unmet need for family planning and women's high levels of knowledge of family planning, there clearly exist barriers to family planning uptake. Stephenson and Hennink have demonstrated that the urban poor experience economic, cultural, cognitive and administrative barriers to family planning service use. ${ }^{36}$ This article extends previous research by examining the health service factors that influence contraceptive uptake among women attending health facilities in urban Pakistan. A greater understanding of these factors may help identify characteristics of the health service environment that can be harnessed or changed to improve service delivery.

\section{DATA AND METHODS}

\section{Sample}

The data for this analysis come from a study that used a multistage cluster sample of health facilities in Pakistan, their health staff and their clients. ${ }^{37}$ Because the original study was concerned with franchised health services, which in Pakistan are located only in urban areas, the sample is limited to urban facilities. The sample of facilities was obtained by stratifying Pakistani cities into three groups according to population size; 11 cities were selected with probability proportional to size. Within each city, wards in the low- to middle-income areas were systematically sampled and all 993 health facilities within these wards were mapped and listed, regardless of whether they offered family planning services. The private health facilities were then cate- 
gorized as either franchised or nonfranchised, and all franchised health facilities were sampled; for other types of health facilities (private, public and nongovernmental), systematic samples were taken. For each health facility in the study, all health staff who were present during the data collection visit and who were authorized to provide family planning services were interviewed, and exit interviews were conducted with eight randomly selected clients (male or female). Overall, 1,113 providers and 7,431 clients were interviewed in January-September 2001.

The client questionnaire collected data on participants' demographic and socioeconomic characteristics, purpose of visit, satisfaction with services, service preferences and history of family planning use. The provider questionnaire collected information on provider training experience, training quality and client loads. The health facility questionnaire collected data on the activity, features, commodity availability and physical characteristics of the facility.

The present analysis examines the determinants of contraceptive adoption among women who expressed a desire to cease or limit childbearing and attended health facilities (both family planning clinics and general health clinics) that offered family planning services. We excluded men from the analysis due to potential sex differences in the factors influencing contraceptive adoption; we also excluded nulliparous women (due to the very low chances that such women would adopt contraception), women who attended facilities that did not offer family planning, and women who visited the clinic for reasons other than family planning services. The final sample consisted of 851 women aged 15-45 who sought a method of family planning, 295 health facilities and 651 providers.

\section{Measures}

We conceptualize the initiation of contraceptive use as a three-stage process. First, the client is motivated to adopt family planning; second, the provider asks the client about her fertility intentions; third, the client receives a method of family planning. Thus, our outcome of interest was a binary variable for which women were coded as one if they were not currently using a family planning method, wanted to delay or limit their childbearing, were asked about their fertility intentions and received contraceptives (or were referred for sterilization). Women who were already using a method of family planning were coded as zero, to remove repeat users, method switchers and women with side effects from the outcome. Hence, the analysis examines the factors that influence family planning adoption among current nonusers visiting health facilities for contraceptive services.

Stage one in our model, the woman's desire to cease or space childbearing, is influenced mainly by individual and household factors, including socioeconomic and demographic characteristics. Community influences may also play a role at this stage, but the original study did not collect community-level data. Stage two, in which the provider asks the client about her fertility preferences, is presumed to be influenced by provider characteristics, as providers'
TABLE 1. Selected characteristics of health facility clients, health facilities and facility staff in urban Pakistan, 2001

\begin{tabular}{|c|c|}
\hline Characteristic & $\%$ or mean \\
\hline CLIENTS & $(\mathrm{N}=851)$ \\
\hline \multicolumn{2}{|l|}{ Education } \\
\hline No education & 35.7 \\
\hline Primary & 6.3 \\
\hline zsecondary & 57.9 \\
\hline \multicolumn{2}{|l|}{ Parity } \\
\hline $1-2$ & 33.4 \\
\hline 3-4 & 36.2 \\
\hline$\geq 5$ & 30.4 \\
\hline \multicolumn{2}{|l|}{ Age } \\
\hline$\leq 25$ & 24.4 \\
\hline $26-30$ & 37.0 \\
\hline $31-35$ & 24.0 \\
\hline$\geq 36$ & 14.6 \\
\hline Total & 100.0 \\
\hline \multicolumn{2}{|l|}{ Visits } \\
\hline Client wanted to space or limit births & 61.9 \\
\hline Provider asked about her fertility intentions & 58.6 \\
\hline Client received family planning method & 26.4 \\
\hline Client received family planning referral & 18.4 \\
\hline \multirow{2}{*}{\multicolumn{2}{|c|}{$\begin{array}{l}\text { Client wanted to space or limit births, was } \\
\text { asked about her fertility intentions and }\end{array}$}} \\
\hline & 40.2 \\
\hline HEALTH FACILITIES & $(\mathrm{N}=295)$ \\
\hline \multicolumn{2}{|l|}{ Type } \\
\hline Públic & 42.1 \\
\hline Nongovernmental organization & 7.3 \\
\hline Private & 50.6 \\
\hline \multicolumn{2}{|l|}{ Franchise network member } \\
\hline Yes & 40.9 \\
\hline No & 59.1 \\
\hline \multicolumn{2}{|l|}{ Separate family planning service area } \\
\hline Yes & 68.9 \\
\hline No & 31.1 \\
\hline \multicolumn{2}{|c|}{ Family planning educational materials on display } \\
\hline Yes & 76.2 \\
\hline No & 23.8 \\
\hline Total & 100.0 \\
\hline \multicolumn{2}{|l|}{ Service statistics } \\
\hline Mean no. of family planning methods offered & $5.6(0-10)$ \\
\hline Mean \% of offered methods available & $72.0(0-100)$ \\
\hline Mean no. of staff offering family planning services & $6.4(0-29)$ \\
\hline Mean no. of staff doctors & $1.0(0-38)$ \\
\hline Mean $\%$ of doctors among health staff & $18.0(0-100)$ \\
\hline Mean no. of Lady Health Workers & $1.0(0-30)$ \\
\hline Mean no. of family planning clients in prior month & $213.2(0-1,676)$ \\
\hline PROVIDERS & $(\mathrm{N}=651)$ \\
\hline$\%$ with in-service family planning training & 78.0 \\
\hline$\%$ female & 86.0 \\
\hline Mean yrs. of family planning experience & $9.6(0-35)$ \\
\hline
\end{tabular}

actions are the product of their training, work activities and background characteristics. Stage three, in which the client receives a method of family planning, is assumed to be mediated by health facility characteristics, such as client volumes, staffing levels, the range of methods offered and the availability of those methods.

The independent variables in the regression analysis are grouped according to the stages of the conceptual frame- 


\begin{tabular}{|c|c|}
\hline Characteristic & Odds ratio \\
\hline \multicolumn{2}{|l|}{ CLIENTS } \\
\hline \multicolumn{2}{|l|}{ Education } \\
\hline No education (ref) & 1.0 \\
\hline Primary & $1.09(0.62-1.56)$ \\
\hline$\geq$ secondary & $1.77(1.32-2.21)^{*}$ \\
\hline \multicolumn{2}{|l|}{ Parity } \\
\hline $1-2$ (ref) & 1.0 \\
\hline $3-4$ & $4.98(4.45-5.50)^{*}$ \\
\hline$\geq 5$ & $9.34(8.77-9.90)^{*}$ \\
\hline \multicolumn{2}{|l|}{ PROVIDERS } \\
\hline Mean yrs. of family planning experience & $0.96(0.92-0.99)^{*}$ \\
\hline$\%$ with in-service family planning training & $0.82(0.21-1.42)$ \\
\hline$\%$ of female providers & $1.73(0.87-2.58)$ \\
\hline \multicolumn{2}{|l|}{ HEALTH FACILITIES } \\
\hline \multicolumn{2}{|l|}{ Type } \\
\hline Public (ref) & 1.0 \\
\hline Nongovernmental organization & $1.82(0.96-2.56)$ \\
\hline Private & $1.13(0.95-1.18)$ \\
\hline \multicolumn{2}{|l|}{ Franchise network member } \\
\hline No (ref) & 1.0 \\
\hline Yes & $1.56(0.97-1.83)$ \\
\hline \multicolumn{2}{|l|}{ Separate family planning service area } \\
\hline No (ref) & 1.0 \\
\hline Yes & $1.39(0.94-1.83)$ \\
\hline \multicolumn{2}{|c|}{ Family planning educational materials on display } \\
\hline No (ref) & 1.0 \\
\hline Yes & $1.78(1.25-2.30)^{*}$ \\
\hline No. of family planning methods offered & $1.04(0.26-1.82)$ \\
\hline$\%$ of offered methods available & $2.38(1.73-3.02)^{*}$ \\
\hline No. of staff offering family planning services & $1.26(1.24-1.27)^{*}$ \\
\hline No. of staff doctors & $1.21(1.04-1.38)^{*}$ \\
\hline$\%$ of doctors among staff & $0.77(0.37-1.17)$ \\
\hline No. of Lady Health Workers & $0.77(0.54-0.99)^{*}$ \\
\hline No. of family planning clients in prior month & $1.02(1.01-1.03)^{*}$ \\
\hline
\end{tabular}

work. For stage one, only the client's parity and level of educational attainment are included as categorical variables; the analysis sample is a clinic-based population with an expressed desire to cease or limit childbearing and thus is already selected on many of the socioeconomic and demographic characteristics that influence health service use and the decision to adopt family planning. For stage two, the model considers three continuous variables: the mean number of years of family planning experience among providers at the facility, the percentage of these providers who have received in-service training in family planning and the percentage of family planning providers at the facility who are female. For stage three, the model considers the number of family planning methods offered by the facility, the num-

*The Lady Health Workers program was established during the 1990s to increase the availability of family planning services among rural and urban poor populations. It uses community-based Lady Health Workers to deliver information, provide services (such as distributing contraceptives) and, if appropriate, refer clients to health facilities. ber of staff offering family planning services, the number of doctors and Lady Health Workers* present at the facility, the proportion of medical staff who are doctors and the proportion of methods offered that were available at the time of the survey; all of these are continuous variables. Finally, the model considers the type of health facility (public, private, nongovernmental organization), whether the facility has a separate area for family planning service provision, and whether the facility displays family planning information, education and communication materials.

\section{RESULTS}

The majority of the women in the analysis were well educated: Some $58 \%$ had a secondary or higher education, which is not surprising given that the data are drawn from a clinic-based population (Table 1, page 73). Nearly equal proportions of participants had one or two children (33\%), three or four children (36\%) or five or more children (30\%). Sixty-one percent of the women were 30 or younger. Sixtytwo percent said they wanted to cease or space childbearing, 59\% had been asked about their fertility intentions by a provider and almost half had received either a method of contraception (26\%) or a referral for contraceptive services (18\%). Overall, $40 \%$ met all three criteria for the outcome variable, i.e., they wanted to cease or space childbearing, had been asked about their fertility intentions and had received contraceptives or a referral for contraceptive services.

About half of the health facilities were privately owned. Most facilities had a separate area for family planning services and displayed educational material. On average, the facilities offered 5.6 contraceptive methods, most of which were in stock. Although only $18 \%$ of staff members who provided family planning services were doctors, almost $80 \%$ of providers had received in-service family planning training. The vast majority were female.

In the multivariate logistic regression, both client factors were associated with the receipt of a family planning method (Table 2). Compared with women with no education, those with secondary or higher education had significantly higher odds of receiving a method of family planning (odds ratio, 1.8). The odds were also significantly higher among women who had three or four children (5.0) or five or more children (9.3) than among women who had only one or two children.

Several provider and health facility characteristics were significant predictors of receipt of services. Higher levels of provider family planning experience were associated with a reduced likelihood that clients would receive a family planning method (odds ratio, 0.96). Women visiting health facilities that displayed educational materials on family planning were significantly more likely than women visiting other facilities to receive contraceptives (1.8). Although the number of family planning methods offered by the health facility was not associated with receipt of services, the odds of receiving contraceptives rose with the proportion of methods usually offered at the facility that were available at the time of the survey (2.4). 
Two measures of health facility staffing levels were positively associated with the receipt of family planning methods: the number of staff who offered family planning services (odds ratio, 1.3 ) and the number of doctors at the facility (1.2). However, the odds of receiving a method of family planning were negatively associated with the number of Lady Health Workers at the facility (0.8). Finally, the number of family planning clients who had attended the clinic in the month prior to the survey was positively associated with a woman's odds of receiving a family planning method (1.02).

\section{DISCUSSION}

This analysis examined the client, provider and health facility characteristics associated with the receipt of contraceptive services among women in urban Pakistan. Previous studies of the factors associated with contraceptive adoption have concentrated on individual and household variables. For example, in a study focusing on the urban poor in Pakistan, Stephenson and Hennink concluded that women faced major economic, social and administrative barriers to obtaining family planning services. ${ }^{38}$ The sample in the present study, however, represents a very select group of women: those who not only wanted to space or cease childbearing but who also had overcome the substantial social and economic barriers to obtaining services. In prior studies, access to reproductive health services was significantly related to higher levels of educational attainment, ${ }^{39}$ economic status ${ }^{40}$ and female autonomy, ${ }^{41}$ because the women in this sample were probably wealthier, better educated and more autonomous than women in the general population, the results of this analysis may not apply to the general population of women of reproductive age.

Even within this sample of women, both the respondent's level of educational attainment and her parity were associated with the likelihood that she would obtain a method. Women with at least a secondary education and those with three or more children were significantly more likely than women with less education or fewer children, respectively, to be asked if they wanted to cease or space childbearing and to receive a method of contraception. The association between parity and the receipt of a method likely reflects two processes: Women of higher parity were more likely to want to adopt contraception and more likely to be asked by providers if they wished to use contraceptives. The effect of education suggests that even after overcoming the barriers to obtaining services, women with higher levels of education had a substantial advantage in terms of receiving a method. This may reflect an association between educational attainment and wealth; women with higher levels of education may have been more able to afford contraceptives. Alternatively, educated women may have been better able to articulate their fertility desires or may have received more favorable attention from providers. Previous studies of family planning services have found that providers tend to be biased toward more educated clients; ${ }^{42}$ conversely, the poor and uneducated often feel that they lack power when interacting with service providers.

At the provider level, the only variable associated with the outcome was experience in providing family planning services. The relationship was negative, indicating that women were less likely to be asked about their fertility desires and to receive contraceptives when providers were highly experienced. The model controlled for the level of in-service training that providers had received, so it is unlikely that this negative relationship reflects a lack of training among more experienced providers. Instead, the association may indicate that providers with more experience were generally older; previous research has suggested that client-provider interactions are more likely to be client centered (and thus more effective) when the provider is younger than $30 .{ }^{43}$ In addition, younger providers are not only more likely than older providers to be similar in age to the client but may also have less traditional views regarding fertility and contraception. Last, in Pakistani society, particular importance is placed on respecting elders, and thus a younger client may feel intimated by or unable to communicate freely with an older provider, reducing the likelihood that she will receive the service she desires.

The analysis also explored the influence of provider gender on the outcome. The proportion of providers at the health establishment who were female was not related to a woman's likelihood of receiving contraceptives; this is a surprising result in the context of Pakistan, where the practice of purdah limits women's access to male health care providers (e.g., under purdah, a woman would not be able to be examined by a male provider and would feel uncomfortable discussing issues of fertility and reproduction with a man).

Our findings underline the importance of the characteristics of health facilities in women's adoption of contraception. Women attending health establishments where family planning information materials were on display and where a larger percentage of the family planning methods usually offered were available at the time of the survey were more likely to receive contraceptives. Both of these results point to the importance of the facility's preparedness to provide quality family planning services. The presence of educational materials demonstrates that the health facility is attempting to inform its clients. Having a large percentage of offered family planning methods in stock reflects the facility's ability to provide a range of family planning methods, and increases the likelihood that the client will be able to receive her method of choice. In addition, the presence of educational materials and adequate contraceptive supplies indicates that the establishment has an organizational infrastructure that supports the provision of family planning services.

Two indicators of personnel capacity were positively related to women's receipt of services-the percentage of staff who offered family planning services and the number of doctors who worked at the facility-and suggest a relationship between organizational capacity and the provision of services. There was also a positive relationship between 
women's receipt of services and a facility's family planning client volume in the month prior to the survey. This finding may indicate that high-quality facilities attract the most clients; hence, women at the more popular health establishments may be more likely to receive quality service.

The number of Lady Health Workers associated with a given facility was negatively associated with receipt of services, a surprising result that conflicts with findings from previous studies. ${ }^{44}$ As noted earlier, the Lady Health Worker program uses community-based health workers to deliver information and some family planning services; the negative association between the number of Lady Health Workers and family planning adoption suggests that although these health providers may be effective in reaching the community, such community outreach programs must not operate at the expense of clinic-based services, and health facilities must ensure that both their communityand site-based family planning services can meet the needs of clients wishing to adopt a method of family planning.

\section{CONCLUSIONS}

This analysis has examined factors associated with a threestage process by which women visiting health facilities in urban Pakistan adopt a method of family planning. The results demonstrate two important issues in the delivery of family planning services in Pakistan. First, there is a direct association between indicators of quality of care and uptake of contraceptive methods, such that uptake is more likely at health establishments with greater availability of staff and methods. Second, the client's own characteristics strongly influence whether she will receive contraceptives. The findings point to several areas of potential intervention at both the client and health establishment level. Providers need to be sensitive to the differing needs of clients with varying levels of education and parity; it may be necessary to target information on family planning to women with lower levels of education who currently have lower uptake of contraception. Additionally, gains in service quality can be achieved through efforts to provide diversity in method choice and greater staff presence, and by improving institutional capacity for service provision. In particular, the negative association between the extent of providers' family planning experience and client contraceptive adoption suggests the need for training that gives providers not only up-to-date family planning information but also instruction on effective client communication, so that barriers in communication that may exist between younger clients and older providers can be surmounted.

\section{REFERENCES}

1. Ministry of Finance, Economic Survey of Pakistan 2003-04, 2005, http://www.finance.gov.pk/survey/home.htm, accessed Dec. 5, 2004; and United Nations Population Fund (UNFPA), State of World Population 2004: The Cairo Consensus at Ten: Population, Reproductive Health and the Global Effort to End Poverty, New York: UNFPA, 2004.

2. Sathar ZA and Casterline JB, The onset of fertility transition in Pakistan, Population and Development Review, 1998, 24(4):773-791; Feeney G and Alam I, New estimates and projections of population growth in
Pakistan, Population and Development Review, 2003, 29(3):483-492; National Institute for Population Studies and IRD/Macro International, Pakistan Demographic and Health Survey, 1990-1991, Columbia, MD, USA: Macro International, 1992; Hakim A, Sultan M and Uddin F, Pakistan Reproductive Health and Family Planning Survey, 2000-2001, Preliminary Report, Islamabad, Pakistan: National Institute for Population Studies, 2001

3. UNFPA, Pakistan Population Assessment 2003, 2003, <http://www.un. org.pk/unfpa/cpa.pdf>, accessed Nov. 12, 2004.

4. Mahmood N and Ringheim K, Factors affecting contraceptive use in Pakistan, Pakistan Development Review, 1996, 35(1):1-22.

5. Mahmood N and Ringheim K, 1996, op. cit. (see reference 4); Shelton JD et al., Putting unmet need to the test: community-based distribution of family planning in Pakistan, International Family Planning Perspectives, 1999, 25(4):191-195; and Rukanuddin AR and HardeeCleaveland K, Can family planning succeed in Pakistan? International Family Planning Perspectives, 1992, 18(3):109-111 \& 121.

6. National Institute for Population Studies and IRD/Macro International, 1992, op. cit. (see reference 2); and Hakim A, Sultan M and Uddin F, 2001 , op. cit. (see reference 2)

7. Hakim A, Sultan M and Uddin F, 2001, op. cit. (see reference 2).

8. Ibid.

9. Government of Pakistan Planning Commission, Eighth Five Year Plan (1993-98), Islamabad, Pakistan: Printing Corporation of Pakistan Press, 1994.

10. UNFPA, 2004, op. cit. (see reference 1).

11. Pakistan Voluntary Health and Nutrition Association, <http://www. pavhna.org>, accessed Dec. 6, 2004.

12. Taking It Global, Family Planning Association of Pakistan, <http:// orgs.takingitglobal.org/2960>, accessed Dec. 9, 2004.

13. Karim MS et al., Family planning: a situation analysis of programs and policies and future directions, in: Bhutta ZA, ed., Maternal and Child Health in Pakistan: Challenges and Opportunities, Karachi, Pakistan: Oxford University Press, 2004, pp. 87-108.

14. Ibid.

15. UNFPA, 2004, op. cit. (see reference 1); and Stephenson RB et al, Franchising reproductive health services, Health Services Research, 2004, 39(6 Pt. 2):2053-2080.

16. Magadi MK, Madise NJ and Rodrigues RN, Frequency and timing of antenatal care in Kenya: explaining the variations between women of different communities, Social Science $\&$ Medicine, 2000, 51(4):551561; and Kavitha N and Audinarayana N, Utilization and determinants of selected MCH care services in rural areas of Tamil Nadu, Health and Population-Perspectives and Issues, 1997, 20(3):112-125.

17. Fikree FF et al., What influences contraceptive use among young women in urban squatter settlements of Karachi, Pakistan? International Family Planning Perspectives, 2001, 27(3):130-136.

18. Bhatia J and Cleland J, Determinants of maternal care in a region of South India, Health Transition Review, 1995, 5(2):127-142.

19. Obermeyer CM and Potter JE, Maternal health care utilization in Jordan: a study of patterns and determinants, Studies in Family Planning, 1991, 22(3):177-187.

20. Griffiths $P$ and Stephenson R, Understanding users' perspectives of barriers to maternal health care use in Maharashtra, India, Journal of Biosocial Science, 2001, 33(3):339-359; and Bloom SS, Lippeveld T and Wypij D, Does antenatal care make a difference to safe delivery? A study in urban Uttar Pradesh, India, Health Policy and Planning, 1999, 14(1):38-48.

21. Magadi MK, Madise NJ and Rodrigues RN, 2000, op. cit. (see reference 16); Bhatia J and Cleland J, 1995, op. cit. (see reference 18); Fikree FF et al., 2001, op. cit. (see reference 17); Addai I, Demographic and sociocultural factors influencing use of maternal health service in Ghana, African Journal of Reproductive Health, 1998, 2(1):73-80; Nuwaha F and Amooti-Kaguna B, Predictors of home deliveries in Rakai District, Uganda, African Journal of Reproductive Health, 1999, 3(2):79-86; and Obermeyer CM, Culture, maternal health care, and women's status: a 
comparison of Morocco and Tunisia, Studies in Family Planning, 1993 , 24(6):354-365.

22. Addai I, 1998, op. cit. (see reference 21).

23. Magadi MK, Madise NJ and Rodrigues RN, 2000, op. cit. (see reference 16); and Bloom SS, Lippeveld T and Wypij D, 1999, op. cit. (see reference 20).

24. Kavitha N and Audinarayana N, 1997, op. cit. (see reference 16).

25. Addai I, 1998, op. cit. (see reference 21).

26. Nuwaha F and Amooti-Kaguna B, 1999, op. cit. (see reference 21).

27. Basu AM, Cultural influences on health care use: two regional groups in India, Studies in Family Planning, 1990, 21(5):275-286.

28. Casterline JB, Sathar ZA and Haque M, Obstacles to contraceptive use in Pakistan, Studies in Family Planning, 2001, 32(2):95-110.

29. Koenig MA, Hossain MB and Whittaker M, The influence of quality of care upon contraceptive use in rural Bangladesh, Studies in Family Planning, 1997, 28(4):278-289; Magnani RJ et al., The impact of the family planning supply environment on contraceptive intentions and use in Morocco, Studies in Family Planning, 1999, 30(2):120-132; and Mensch B, Arends-Kuenning M and Jain A, The impact of the quality of family planning services on contraceptive use in Peru, Studies in Family Planning, 1996, 27(2):59-75.

30. Speizer IS and Bollen KA, How well do perceptions of family planning service quality correspond to objective measures? Evidence from Tanzania, Studies in Family Planning, 2000, 31(2):163-177.

31. Basu AM, 1990, op. cit. (see reference 27); and Sultan M, Cleland JC and Ali MM, Assessment of a new approach to family planning services in rural Pakistan, American Journal of Public Health, 2002, 92(7):1168-1172.

32. Jain AK, Fertility reduction and the quality of family planning services, Studies in Family Planning, 1989, 20(1):1-16.

33. Blanc AK, Curtis SL and Croft TN, Monitoring contraceptive continuation: links to fertility outcomes and quality of care, Studies in Family Planning, 2002, 33(2):127-140.

34. Koenig MA, Hossain MB and Whittaker M, 1997, op. cit. (see reference 29).

35. Sultan M, Cleland JC and Ali MM, 2002, op. cit. (see reference 31).

36. Stephenson RB and Hennink M, Barriers to family planning service use among the urban poor in Pakistan, Asia-Pacific Population Journal, 2004, 19(2):5-26.

37. Carolina Population Center, Alternative business models for family planning, 2005, <http://www.cpc.unc.edu/projects/abm/>, accessed April 19, 2006.

38. Stephenson RB and Hennink M, 2004, op. cit. (see reference 36).

39. Addai I, 1998, op. cit. (see reference 21); and Nuwaha F and AmootiKaguna B, 1999, op. cit. (see reference 21).

40. Kavitha N and Audinarayana N, 1997, op. cit. (see reference 16).

41. Obermeyer CM, 1993, op. cit. (see reference 21).

42. Schuler SR and Hossain Z, Family planning clinics through women's eyes and voices: a case study from rural Bangladesh, International Family Planning Perspectives, 1998, 24(4):170-175 \& 205.

43. Abdel-Tawab $\mathrm{N}$ and Rotter $\mathrm{D}$, The relevance of client-centered communication to family planning settings in developing countries: lessons from the Egyptian experience, Social Science \& Medicine, 2002, 54(9): 1357-1368.

44. Sultan M, Cleland JC and Ali MM, 2002, op. cit. (see reference 31).

\section{RESUMEN}

Contexto: Si bien la inmensa mayoría de las mujeres paquistaníes están familiarizadas con los métodos de planificación familiar, el uso de anticonceptivos continúa siendo aún muy bajo. La identificación de las características de los proveedores de servicios de planificación familiar que están relacionadas con la iniciación del uso anticonceptivo puede asistir a los administradores de los programas en la preparación de las intervenciones destinadas a incrementar el uso.

Métodos: Mediante análisis de regresión logística, se examinaron los resultados de una encuesta de instalaciones de salud de zonas urbanas de Pakistán que indagaba sobre las clientas y el personal de salud para identificar las características de las clientas, de los proveedores y de las clínicas que indicaran si las mujeres recibieron anticonceptivos durante sus visitas a las clínicas urbanas.

Resultados: Las mujeres que tenían un nivel educativo de enseñanza secundaria o superior y las que tenían tres o más hijos presentaban unas elevadas probabilidades de haber recibido un método (razones de momios, 1,8-9,3). Las mujeres tenían menores probabilidades de recibir un método cuando los proveedores tenían más experiencia en servicios de planificación familiar. Las mujeres que asistían a las instalaciones que disponían de material educativo sobre planificación familiar presentaban mayores probabilidades de haber recibido dichos servicios (1,8), y estas probabilidades aumentaban con la proporción de los métodos anticonceptivos que estaban a disposición en la clínica y con el número de médicos y de personal que ofrecía servicios $(1,2-2,4)$.

Conclusión: Los proveedores deben estar al tanto de las necesidades de anticoncepción entre las mujeres de todos los niveles de educación y paridad. Además, las instalaciones de planificación familiar podrían aumentar el uso anticonceptivo de sus clientas si ofrecen una mayor diversidad de métodos, mantienen un buen abastecimiento de anticonceptivos en la clínica, exponen material informativo y aumentan la cantidad del personal.

\section{RÉSUMÉ}

Contexte: Bien que la grande majorité des Pakistanaises soient au courant des méthodes de planification familiale, l'usage de contraceptifs demeure faible. L'identification des caractéristiques des prestataires et centres de planification familiale associés à l'adoption de la contraception par les femmes peut aider les administrateurs de programmes à définir les interventions aptes à accroître la pratique contraceptive.

Méthodes: L'analyse de régression logistique des données d'une étude d'établissements de santé pakistanais urbains, de leur clientèle et de leur personnel a permis d'identifier les caractéristiques individuelles, de prestataire et d'établissement prédictives de la réception de contraceptifs lors des visites des fermmes dans les cliniques urbaines.

Résultats: La probabilité de réception d'une méthode s'est avérée élevée pour les femmes scolarisées au niveau secondaire ou supérieur et mères d'au moins trois enfants (rapport de probabilités, 1,8-9,3). Elle était réduite dans les établissements où les prestataires présentaient de plus hauts niveaux d'expérience de la planification familiale. Elle était élevée dans les établissements affichant un matériel de sensibilisation à la planification familiale (1,8), et ce de manière proportionnelle aux méthodes contraceptives disponibles en stock, au nombre de médecins et au nombre de membres du personnel affectés à la 
planification familiale (1,2 à 2,4).

Conclusion: Les prestataires doivent être conscients des besoins de contraception des femmes de tous niveaux d'instruction et parité. De plus, les établissements de planification familiale pourraient vraisemblablement accroître la pratique contraceptive de leurs clientes en offrant une diversité de choix de méthodes, en gardant les méthodes proposées en stock, en affichant un matériel d'information et en accroissant leurs niveaux de personnel.

\section{Acknowledgments}

The data analyzed in this paper were collected by Aftab Associates (now A. C. Neilson Aftab) for Greenstar Social Marketing with support from the David and Lucile Packard Foundation, which also supported technical assistance from the Carolina Population Center, University of North Carolina at Chapel Hill. The authors also gratefully acknowledge support from the Gates Institute for Population and Reproductive Health, Johns Hopkins Bloomberg School of Public Health.

Author contact: rbsteph@sph.emory.edu

NEW EXPANDED VERSION AVAILABLE AUGUST 2006

\section{International Family Planning Perspectives on CD}

Access 15 years of peer-reviewed research on sexual and reproductive health, originally published in International Family Planning Perspectives, from your computer desktop. The new IFPP CD contains more than 1,000 searchable, printable PDF files from issues published between 1990 and 2004.

To receive your free $C D$, please fill out a request form at www.guttmacher.org/cd_rom/index.html.

To receive the request form, please email us at buyit@guttmacher.org, or write to us at: Guttmacher Institute 120 Wall Street, NY, NY, 10005, EEUU

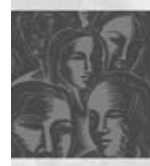

INTERNATIONAL FAMILY PLANNING PERSPECTIVES on CD

Articles published in the Guttmacher Institute's peer-reviewed journal

1990-2004 This CD archive is a ioint proiect of the Guttmocher Perspectives, and the Information and Knowledge for Optimal Health (INFO) Project of the Center for Communications Programs at Johns Hopkins University, Bloomberg School of Public Health. 